\title{
Solving the puzzle of mirror-image flowers
}

\section{The genetically controlled orientation of floral sex organs encourages cross-pollination.}

nantiostyly is a plant sexual polymorphism in which female sex organs are deflected to the left or right - resulting in 'mirror-image' flowers - but, although it occurs in at least a dozen unrelated families of flowering plants ${ }^{1}$ and has been known for over a century ${ }^{2}$, its adaptive significance has been unclear. Here we show that a mendelian locus governs the inheritance of style orientation and that this curious form of sexual asymmetry functions to promote cross-pollination in bee-pollinated plants.

To investigate whether enantiostyly is genetically determined, we carried out controlled crosses on Heteranthera multiflora, a species with left- and right-styled plants. Progeny ratios in families of the first and second generations $\left(F_{1}\right.$ and $\left.F_{2}\right)$ indicated that style deflection is governed by a mendelian locus at which the right-styled allele $(R)$ is dominant to left $(r)$.

All crosses between genotypically homozygous plants with opposite style orientations ( 8 families, $n=242$ progeny)

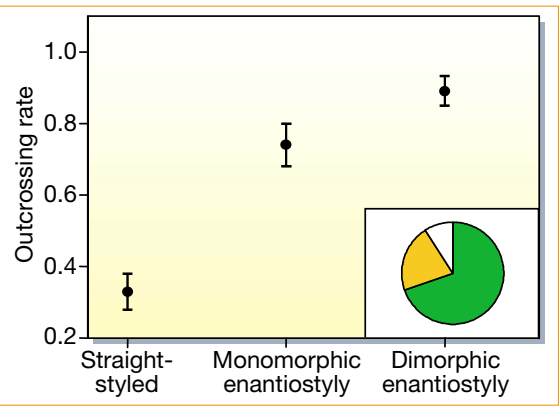

Figure 2 Enantiostyly influences mating patterns in experimental arrays of Solanum rostratum. Mean outcrossing rates were determined by using polymorphic allozyme loci ${ }^{6}$ for different style orientations in arrays of 16 plants (trimmed to 6 flowers per plant) in a square grid (4 replicates each). Straight-styled plants, the style was tied to the base of the pollinating anther with clear nylon thread; monomorphic enantiostyly, left- and right-styled flowers on the same plant; dimorphic enantiostyly, flowers were removed to create arrays that were entirely left- or right-styled. Outcrossing rates were estimated for all array types; the frequency of interand intramorph mating was determined for dimorphic arrays. Array type had no significant effect on the mean number of flowers visited per plant by bumble-bees (log-likelihood ratio, 4.11; $P=0.39$ ), which did not discriminate between left- and rightstyled flowers (log-likelihood ratio, 2.46; $P=0.12$ ). Values are means \pm s.e. based on 1,000 bootstrap estimates; ANOVA was used for outcrossing-rate differences, with the effect of each observation weighted by the inverse of its squared standard error to account for variation in the estimates ${ }^{6}$. Outcrossing rates differed significantly between the three treatments (ANOVA: $F=40.38 ;$ d.f. $=2 ; P<0.001 ;$ a priori contrasts: straight-styled vs monomorphic enantiostylous, $F=21.43$; d.f. $=1 ; P=0.001$ monomorphic vs dimorphic, $F=59.33$; d.f. $=1 ; P<0.001$ ). Inset, frequency of intermorph (green), intramorph (orange) and selfed (white) mating events in dimorphic enantiostylous arrays.
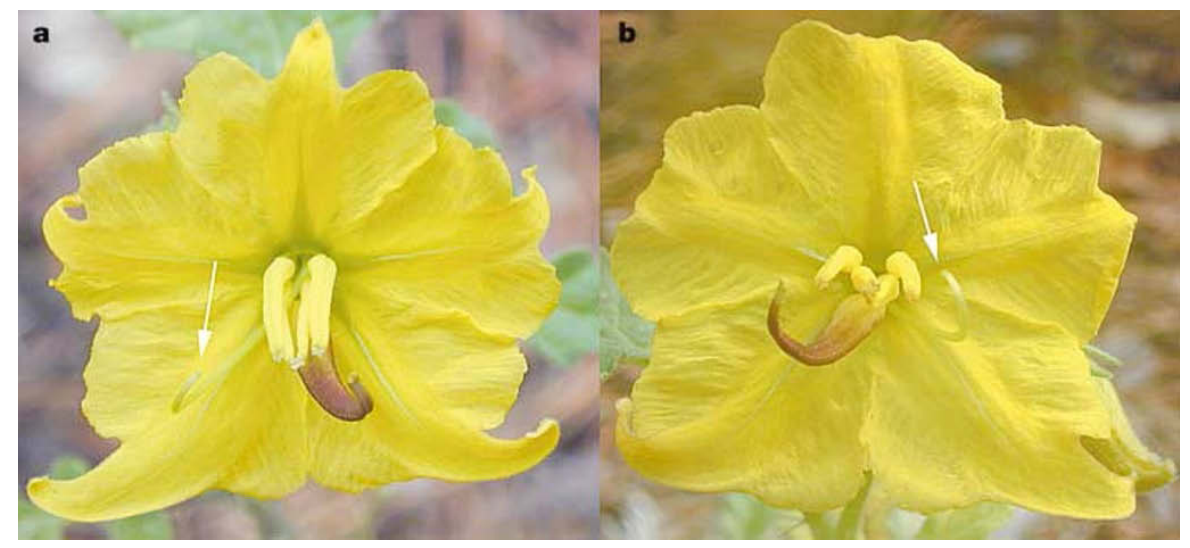

Figure 1 The 'mirror-image' flowers of Solanum rostratum. a, Left-styled flower; $\mathbf{b}$, right-styled flower. Styles are indicated by arrows.

produced only right-styled plants. All $\mathrm{F}_{2}$ segregations conformed to the expected 3:1 ratio of right- to left-styled plants ( 6 families, $n=242$ progeny; right, 0.76 ; left, 0.24 ; deviation from $3: 1, G_{\text {het }}=1.273, P=0.93$; $\left.G_{\text {pooled }}=0.139, P=0.71\right)$. The discovery of a mendelian locus that controls style orientation is, to our knowledge, the first demonstration of a gene for 'handedness' in plants.

With single-locus control of style orientation and equivalent levels of crosspollination between left- and right-styled plants, a 1:1 ratio of the two style morphs should occur in natural populations of enantiostylous plants. This is the case in Wachendorfia paniculata populations ${ }^{3}$, suggesting that polymorphism in this species is also likely to be simply inherited.

Bees visiting enantiostylous flowers pick up pollen on the sides of their bodies, which favours transfer between flowers of opposite style deflection ${ }^{4}$ and suggests that enantiostyly promotes cross-pollination in a way that is functionally analogous to heterostylous sexual polymorphisms ${ }^{5}$. But although this makes sense for enantiostylous species in which plants have one or other stylar direction (dimorphic enantiostyly), species that produce both left- and right-styled flowers on an individual plant (monomorphic enantiostyly) are common and present a problem for the cross-pollination hypothesis ${ }^{1}$. This is because the presence of left- and right-styled flowers on the same plant could promote interfloral self-pollination, resulting in inbreeding depression and loss of outcross mating opportunities through pollen discounting ${ }^{6}$.

However, monomorphic enantiostyly probably evolved from an ancestor with straight styles. In straight-styled plants, all flowers on the plant can potentially donate and receive pollen from one another, whereas between-flower transfer should be relatively reduced in monomorphic enantiostyly (depending on the ratio of left- and right-styled flowers on a plant).

We investigated the role of enantiostyly in promoting cross-pollination in experimental arrays of Solanum rostratum (Fig. 1), a species with monomorphic enantiostyly that is visited primarily by bumblebees $^{4}$. By using marker genes and manipulating the flowers and inflorescences, we compared mating patterns in arrays composed of plants with the same number of flowers, but with each array having one of three stylar arrangements: straight styles, monomorphic enantiostyly or dimorphic enantiostyly (Fig. 2).

We predicted that outcrossing rates should be highest for arrays with dimorphic enantiostyly, lower for those with monomorphic enantiostyly, and lowest in those composed of straight-styled plants. For dimorphic enantiostyly, most mating should also occur between plants with opposite style orientations. Our results confirmed these predictions (Fig. 2).

We have shown that enantiostyly can increase the precision of cross-pollen transfer. The multiple origin of mirror-image flowers among angiosperm families provides a striking example of a convergent floral strategy that promotes pollen dispersal in bee-pollinated plants.

Linley K. Jesson, Spencer C. H. Barrett

Department of Botany, University of Toronto,

25 Willcocks Street, Toronto,

Ontario M5S 3B2, Canada

e-mail:barrett@botany.utoronto.ca

1. Barrett, S. C. H., Jesson, L. K. \& Baker, A. M. Ann. Bot. 85 (suppl. A), 253-265 (2000)

2. Todd, J. E. Am. Nat. 16, 281-287 (1882).

3 Jesson, L. K. \& Barrett, S. C. H. Am. J. Bot. 89, 253-262 (2002).

4. Bowers, K. A. W. Am. J. Bot. 62, 633-638 (1975).

5. Barrett, S. C. H. Nature Rev. Genet. 3, 274-284 (2002).

6. Harder, L. D. \& Barrett, S. C. H. Nature 373, 512-515 (1995).

Competing financial interests: declared none. 